\title{
Strong electron correlations stabilize paramagnetic cubic Cr1-xAlxN solid solutions
}

\author{
Björn Alling, L Hultberg, Lars Hultman and Igor Abrikosov
}

\section{Linköping University Post Print}

N.B.: When citing this work, cite the original article.

Original Publication:

Björn Alling, L Hultberg, Lars Hultman and Igor Abrikosov, Strong electron correlations stabilize paramagnetic cubic Cr1-xAlxN solid solutions, 2013, Applied Physics Letters, (102), 3, .

http://dx.doi.org/10.1063/1.4788747

Copyright: American Institute of Physics (AIP) http://www.aip.org/

Postprint available at: Linköping University Electronic Press http://urn.kb.se/resolve?urn=urn:nbn:se:liu:diva-89520 


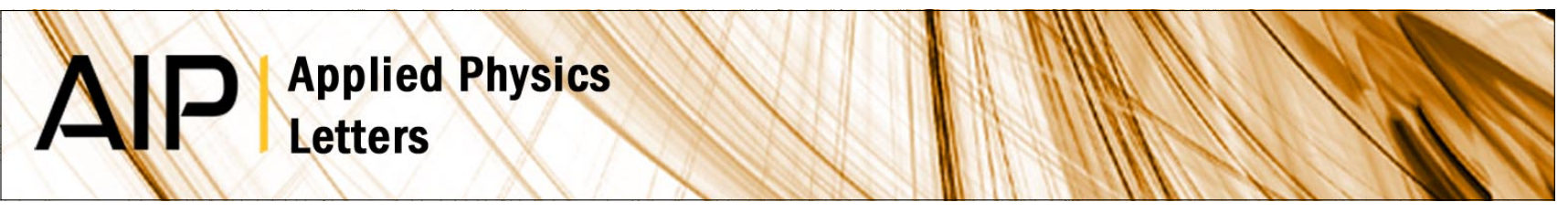

\section{Strong electron correlations stabilize paramagnetic cubic $\mathrm{Cr} 1-\mathrm{xAlxN}$ solid solutions}

B. Alling, L. Hultberg, L. Hultman, and I. A. Abrikosov

Citation: Appl. Phys. Lett. 102, 031910 (2013); doi: 10.1063/1.4788747

View online: http://dx.doi.org/10.1063/1.4788747

View Table of Contents: http://apl.aip.org/resource/1/APPLAB/v102/i3

Published by the American Institute of Physics.

\section{Related Articles}

Chirality distribution in single walled carbon nanotube films by spectroscopic ellipsometry Appl. Phys. Lett. 102, 091909 (2013)

Study of the Fe-Al alloys in the Ising model for $\mathrm{S}=2$ spin by employing the effective field theory

J. Appl. Phys. 113, 093903 (2013)

Ni6Cr5MoO18: A compensated half metal predicted from first-principles

J. Appl. Phys. 113, 043718 (2013)

Gate controlled coupling of intersubband plasmons

Appl. Phys. Lett. 102, 031102 (2013)

Terahertz resonances due to edge magnetoplasmons in a wide armchair graphene ribbon with a weak superlattice potential

AlP Advances 2, 042161 (2012)

\section{Additional information on Appl. Phys. Lett.}

Journal Homepage: http://apl.aip.org/

Journal Information: http://apl.aip.org/about/about_the_journal

Top downloads: http://apl.aip.org/features/most_downloaded

Information for Authors: http://apl.aip.org/authors

\section{ADVERTISEMENT}

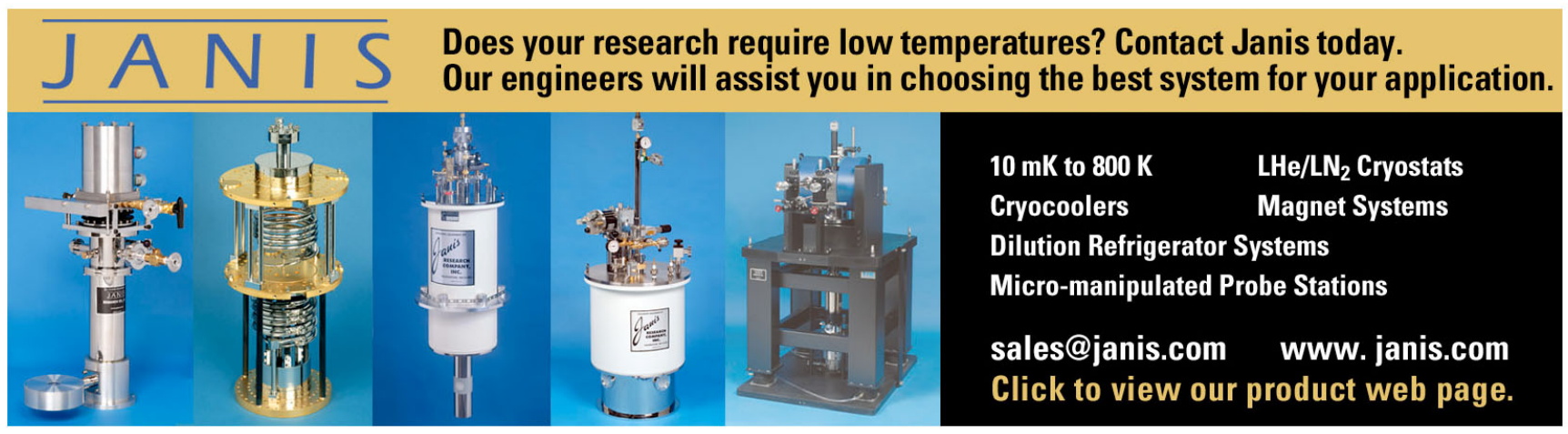




\title{
Strong electron correlations stabilize paramagnetic cubic $\mathrm{Cr}_{1-x} \mathrm{Al}_{x} \mathrm{~N}$ solid solutions
}

\author{
B. Alling, ${ }^{1}$ L. Hultberg, ${ }^{2}$ L. Hultman, ${ }^{1}$ and I. A. Abrikosov ${ }^{2}$ \\ ${ }^{1}$ Thin Film Physics Division, Department of Physics, Chemistry, and Biology (IFM), Linköping University, \\ SE-581 83 Linköping, Sweden \\ ${ }^{2}$ Theoretical Physics Division, Department of Physics, Chemistry, and Biology (IFM), Linköping University, \\ SE-581 83 Linköping, Sweden
}

(Received 31 October 2012; accepted 7 January 2013; published online 24 January 2013)

\begin{abstract}
The stability of rock salt structure cubic $\mathrm{Cr}_{1-x} \mathrm{Al}_{x} \mathrm{~N}$ solid solutions at high $\mathrm{Al}$ content and high temperature has made it one of the most important materials systems for protective coating applications. We show that the strong electron correlations in a material with dynamic magnetic disorder is the underlying reason for the observed stability against isostructural decomposition. This is done by using the first-principles disordered local moments molecular dynamics technique, which allows us to simultaneously consider electronic, magnetic, and vibrational degrees of freedom. (C) 2013 American Institute of Physics. [http://dx.doi.org/10.1063/1.4788747]
\end{abstract}

Multicomponent nitrides is a class of materials of utmost importance for protective coatings in, e.g., cutting tool applications. ${ }^{1} \mathrm{Cr}_{1-x} \mathrm{Al}_{x} \mathrm{~N}$ solid solutions is together with the related $\mathrm{Ti}_{1-x} \mathrm{Al}_{x} \mathrm{~N}$ system, one of the most successful materials in this respect. ${ }^{2}$ Together with high hardness, the two systems display excellent wear and oxidation resistance. One striking difference between the two systems is that $\mathrm{Ti}_{1-x} \mathrm{Al}_{x} \mathrm{~N}$, especially with high AlN-content, exhibits spinodal decomposition into rock salt $\mathrm{AlN}$ and TiN-rich domains at temperatures around $800-900{ }^{\circ} \mathrm{C}^{3}$ This isostructural phase separation leads first to beneficial age-hardening, but at somewhat higher temperature to decrease in hardness as AIN is transformed into the wurtzite structure. ${ }^{4} \mathrm{Cr}_{1-x} \mathrm{Al}_{x} \mathrm{~N}$, on the other hand, does not display spinodal decomposition. 5,6 While age hardening due to spinodal decomposition is not present in $\mathrm{Cr}_{1-x} \mathrm{Al}_{x} \mathrm{~N}$, a higher amount of $\mathrm{AlN}$ can be solved in the cubic phase and the integrity of the cubic lattice is retained to higher temperatures making $\mathrm{Cr}_{1-x} \mathrm{Al}_{x} \mathrm{~N}$ the preferred material's choice in many applications. ${ }^{7}$ This is by virtue of the enhancement by the Al alloying of the coating's resistance to oxidation, chemical wear, and recrystallization. Recently, attempts to combine the above effects resulted in promising high hardness of TiCrAlN films at temperatures $\geq 1000^{\circ} \mathrm{C}^{8}$

Previous theoretical calculations have shown that the magnetic polarization of $\mathrm{Cr}$ atoms is important to consider in modeling of $\mathrm{Cr}_{1-x} \mathrm{Al}_{x} \mathrm{~N}$ and when included, the driving force for decomposition was indeed found to be lower than for $\mathrm{Ti}_{1-x} \mathrm{Al}_{x} \mathrm{~N} .{ }^{9,10}$ However, a discrepancy between theory and experiments still exist as isostructural spinodal decomposition at relevant temperatures anyway was predicted by the calculations, ${ }^{9}$ although in a more limited composition range than for $\mathrm{Ti}_{1-x} \mathrm{Al}_{x} \mathrm{~N}$. $^{11}$

Recently, it has become clear that pure $\mathrm{CrN}$, in contrast to $\mathrm{TiN}$, is a material where strong electron correlations, ${ }^{12,13}$ together with the disordered magnetism in its cubic phase $\mathrm{e}^{14}$ are of importance to understand the electronic structure ${ }^{15-17}$ as well as its bulk modulus. ${ }^{18-20}$ Furthermore, it has been shown that particular care must be taken when considering the disordered magnetism together with vibrations or local lattice relaxations. The reason is that a static model of $\mathrm{Cr}$ magnetic moments disorder will induce artificial relaxations of the atomic positions in any supercell treatment. For this reason, the disordered local moments' molecular dynamics (DLM-MD) method was developed to treat paramagnetic materials at elevated temperature by dynamically rearranging the disordered local moments during the simulation. ${ }^{21}$

In this work, we investigate the consequences of strong electron correlations and disordered magnetism for the mixing thermodynamics of cubic $\mathrm{Cr}_{1-x} \mathrm{Al}_{x} \mathrm{~N}$ solid solutions in the $\mathrm{B} 1$ structure. We use DLM-MD calculations ${ }^{21}$ at $300 \mathrm{~K}$ and the local spin density approximation ${ }^{22}$ together with a Hubbard coulomb term $(\mathrm{LDA}+\mathrm{U})^{23,24}$ with the value of $U=3 \mathrm{eV}$ (Ref. 14) applied to the $\mathrm{Cr} 3 d$-orbitals to accurately model the electronic and magnetic structure of $\mathrm{Cr}_{1-x} \mathrm{Al}_{x} \mathrm{~N}$, in addition, giving us insight in the effects of lattice vibrations. Calculations were done using the projector augmented wave method $^{25}$ as implemented in the Vienna Ab-initio Simulation Package (VASP). ${ }^{26}$ A Monkhorst-Pack $3 \times 3 \times 3 \mathrm{k}$-point mesh was used together with an energy cut-off of $400 \mathrm{eV}$. The chemical disorder on the metal sublattice was modeled using the special quasi random structure (SQS) method. ${ }^{27}$ $2 \times 2 \times 2$ conventional cubic supercells with 64 atoms were used in the MD simulations. For comparison purposes, we also performed calculations using static magnetic disorder in a 3-component $\left(\mathrm{Cr}^{\uparrow}, \mathrm{Cr}^{\downarrow}, \mathrm{Al}\right) 128$ atom SQS approximation using both the $\mathrm{LDA}+\mathrm{U}$ and the generalized gradient approximation (GGA) for exchange and correlations effects. $^{28}$ The lattice parameters used in the DLM-MD calculations were taken from the optimal lattice spacings obtained in corresponding static calculations with the LDA $+\mathrm{U}$ approximation. The difference in equilibrium lattice spacing between fully relaxed and unrelaxed lattices was found to be very small. Furthermore, thermal expansion was neglected as its impact on volume for $\mathrm{T}=300 \mathrm{~K}$ was found to be less than $0.2 \%{ }^{21}$ Uncertainties in mixing enthalpies due to $\mathrm{k}$ point sampling was tested and found to be in the order of $0.1 \mathrm{meV} / \mathrm{f} . \mathrm{u}$, while uncertainties due to SQS size was of the order of $1 \mathrm{meV} / \mathrm{f}$.u. for $\mathrm{x}=0.50$. 
Our analysis of the tendencies towards isostructural cubic mixing or decomposition starts with the mixing enthalpies of the random alloys calculated at zero pressure

$$
\begin{aligned}
\Delta H_{\text {mix }}^{\text {rand }}(x)= & H\left(\mathrm{Cr}_{1-x} \mathrm{Al}_{x} \mathrm{~N}\right)-(1-x) H(\mathrm{CrN}) \\
& -x H(\mathrm{c}-\mathrm{AlN}),
\end{aligned}
$$

where the terms on the right are the enthalpies of the $\mathrm{Cr}_{1-x} \mathrm{Al}_{x} \mathrm{~N}$ disordered solid solutions, pure cubic $\mathrm{CrN}$, and pure cubic AlN, respectively. To obtain these enthalpies, DLM-MD calculations at a temperature of $300 \mathrm{~K}$ were done for the concentrations $x=0.00,0.25,0.50$, and 0.75 . Standard non-magnetic first-principles $\mathrm{MD}$ was performed for pure rock salt AlN. In the DLM-MD calculations, a time step of 1 fs was used while the magnetic structures were updated every $5 \mathrm{fs}$. This was done by randomly assigning either spin up or spin down to every local $\mathrm{Cr}$ moments in the supercell. The magnitudes of the local moments are calculated selfconsistently at every step of the MD, and are found to be close to $3 \mu_{B}$ in all cases. The resulting potential energies from MD calculations, corresponding to the electronic total energies of the simulations, are plotted for the Cr-containing cases in Fig. 1. The simulations were performed during 6 ps corresponding to $6000 \mathrm{MD}$ time steps and 1200 different magnetic structures. The energies can be seen to oscillate around stable values with the average values converging smoothly after a short initiation time in the beginning of the simulations. We use the average energies of the last 2000 time steps in the derivation of the mixing enthalpies that thus can be determined to a statistical accuracy of about $0.5 \mathrm{meV} / \mathrm{f}$.u. The inset of Fig. 1 for $\mathrm{x}=0.50$ is a zoom in of the energies during a 60 time steps period. It illustrates how the dynamical update of magnetic structure takes care of the simultaneous averaging of both the magnetic energies, small energy jumps every 5th time step, and the magnetic structure induced forces, small changes in the energy derivatives before and after the jumps, during one single MD simulation.

From these calculations, we can extract the isostructural, rock salt mixing enthalpies, Eq. (1). The mixing enthalpies of the random alloys are plotted as black circles in Fig. 2.

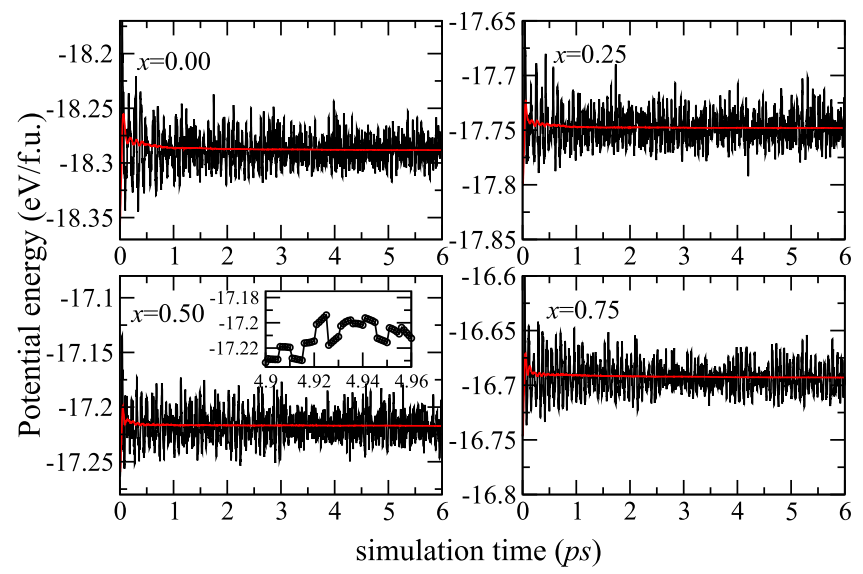

FIG. 1. Calculated DLM-MD potential energies of $\mathrm{Cr}_{1-x} \mathrm{Al}_{x} \mathrm{~N}, x=0.00$, $0.25,0.50$, and 0.75 at $300 \mathrm{~K}$. The red lines are the accumulated average energies. The inset shows a zoom of the energy evolution during a $60 \mathrm{fs}$ time period for $\mathrm{x}=0.50$.

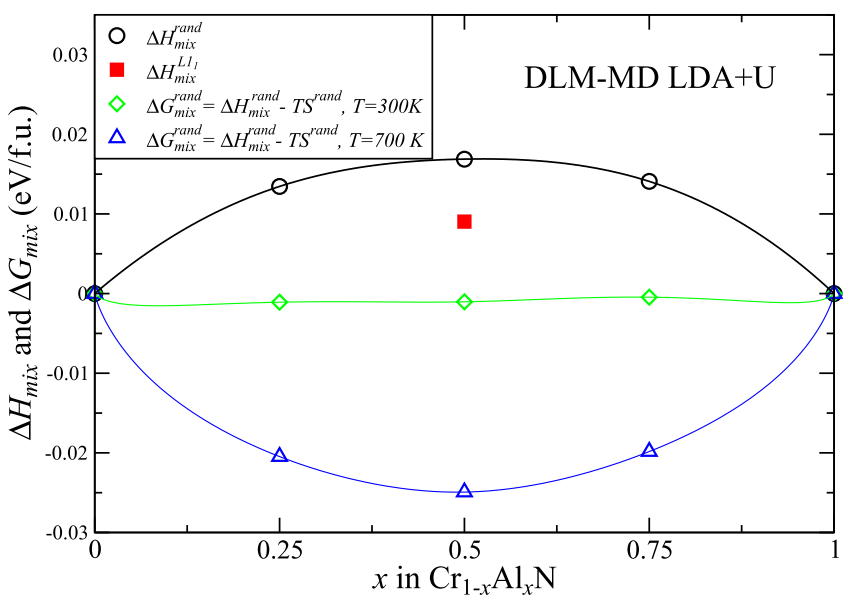

FIG. 2. Mixing enthalpies and free energies of mixing for cubic $\mathrm{Cr}_{1-x} \mathrm{Al}_{x} \mathrm{~N}$ solid solutions. The values of $H_{m i x}$ are obtained with DLM-MD at $300 \mathrm{~K}$ within the LDA + U approximation. The calculated values are marked with symbols while the lines, based on a cubic spline through the enthalpy points, serve as guides for the eye.

They are positive but small, with a maximum value at $\mathrm{x}=0.50$ of $17 \mathrm{meV} / \mathrm{f}$.u. This can be compared to the values obtained using the GGA in Ref. 9 of $74 \mathrm{meV} / \mathrm{f}$.u. for the same composition. For comparison, the value in the strongly clustering system $\mathrm{Ti}_{0.5} \mathrm{Al}_{0.5} \mathrm{~N}$ was found to be about $200 \mathrm{meV} / \mathrm{f} . \mathrm{u}^{11}$ We would like to add that for the case of coherent spinodal decomposition, a small lattice strain would work against separation.

Since the mixing enthalpies of the random alloys are small, one could consider if an ordered compound could be energetically stable. In Fig. 2, the DLM-MD calculated mixing enthalpy of the ordered $\mathrm{L} 1_{1}$ structure, found to be stable in the isostructural $\mathrm{Zr}_{0.5} \mathrm{Gd}_{0.5} \mathrm{~N}$ (Ref. 29) and $\mathrm{Ti}_{0.5} \mathrm{~W}_{0.5} \mathrm{~N}$ (Ref. 30) systems, is shown with a red square. Its enthalpy is lower than for the random alloys, but it is still positive with respect to pure cubic $\mathrm{CrN}$ and cubic AlN. Fig. 2 also shows the free energy of mixing

$$
\Delta G_{m i x}^{\text {rand }}(x)=\Delta H_{m i x}^{\text {rand }}(x)-T S^{\text {rand }}(x),
$$

where $\mathrm{T}$ is the temperature, $S^{\text {rand }}=-k_{B}[x \ln x+(1-x)$ $\ln (1-x)]$ is the mixing entropy per formula unit of an ideal binary solid solution and $\Delta H_{m i x}^{\text {rand }}(x)$ are previously calculated from DLM-MD. Temperature favors mixing and already at $\mathrm{T}=300 \mathrm{~K}, \Delta G_{m i x}^{\text {rand }}$ is close to zero for all compositions. As an illustration, we also estimate the value of $\Delta G_{m i x}^{\text {rand }}$ when the temperature-entropy term is taken at $700 \mathrm{~K}$, a temperature on par with physical vapor deposition synthesis of $\mathrm{Cr}_{1-x} \mathrm{Al}_{x} \mathrm{~N}$. At such a temperature, and at all higher temperatures, the isostructural mixing free energy curve is negative and convex, strongly favoring mixing. Thus, there is no thermodynamic driving force for any type of isostructural decomposition, including spinodal decomposition, in cubic $\mathrm{Cr}_{1-x} \mathrm{Al}_{x} \mathrm{~N}$ at temperatures where diffusion can take place. These results are in line with the experimental observations, although the differences to previous calculations deserve discussion.

The main difference between previous studies of $\mathrm{Cr}_{1-x} \mathrm{Al}_{x} \mathrm{~N}$ and the present work is that the earlier calculations were performed using the GGA approximation for exchange-correlation effects. ${ }^{6,9,10,31}$ Another difference is 


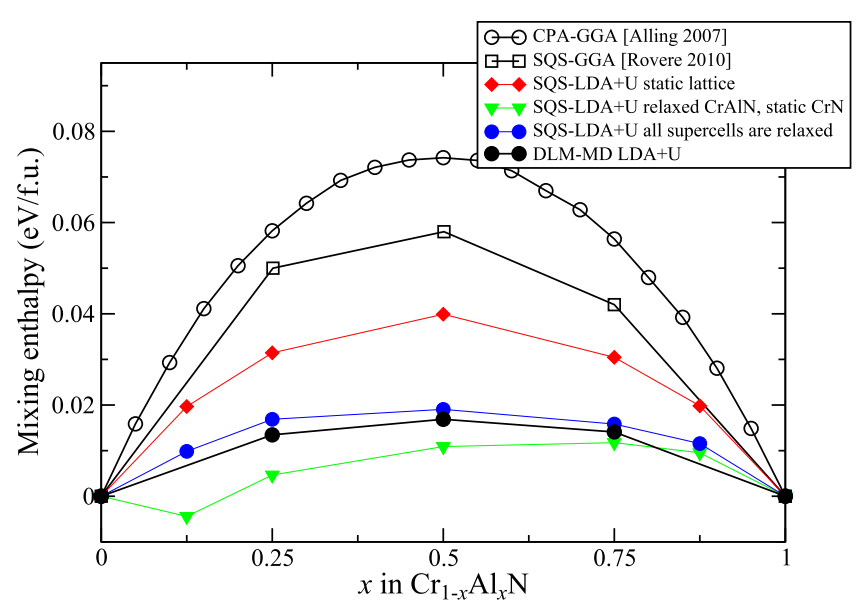

FIG. 3. Calculated mixing enthalpies of cubic paramagnetic $\mathrm{Cr}_{1-x} \mathrm{Al}_{x} \mathrm{~N}$ using different approximations for exchange-correlations and treatments of local lattice relaxations. The GGA calculations were obtained previously by Alling et al. ${ }^{9}$ and Rovere $e t$ al. ${ }^{6}$

that previous calculations were treating lattice relaxation with a relaxation model on top of fixed lattice calculations 9 or with static magnetic orders within fully relaxed super cells. $^{6,10}$ In Fig. 3, we illustrate the impact of considering strong electron correlations on the level of the LDA $+\mathrm{U}$ approximation as well as different treatments of the local lattice relaxation effects. The largest difference comes from the exchange-correlation approximation. GGA results give much higher values of mixing enthalpies as compared to our present calculations were the strongly correlated $\mathrm{Cr} 3 d$-orbitals are treated with the LDA $+\mathrm{U}$ approach. Our own test calculations with GGA, static magnetism, and relaxed lattice give enthalpies a little smaller than those of Rovere et al. ${ }^{6}$ but still larger than our LDA $+\mathrm{U}$ values without relaxations. The origin can be found in the electronic structure of pure $\mathrm{CrN}:{ }^{14}$ When the $\mathrm{Cr} 3 d$-states are more localized they hybridize weaker with neighboring $\mathrm{Cr}$-states. Thus, the introduction of Al that breaks such bonds does not give rise to as high mixing enthalpy as compared to the GGA description for which the $\mathrm{Cr}-\mathrm{Cr}$ bonds are stronger.

The treatment of lattice relaxations is not straightforward in a paramagnetic alloy system such as $\mathrm{Cr}_{1-x} \mathrm{Al}_{x} \mathrm{~N}$. In any static simulation of the paramagnetic $\mathrm{Cr}$ moments, the magnetic-induced interatomic forces are not averaged out, as in reality. For example, pure $\mathrm{CrN}$ treated in a static disordered manner will display large artificial lattice relaxations if allowed to relax. ${ }^{21}$ In pure $\mathrm{CrN}$, an ideal lattice approximation can be done, ${ }^{14}$ but for an alloy, local lattice relaxations are needed. As shown above, the DLM-MD is the ideal method to use although static relaxed supercells has been used previously. Fig. 3 shows the results on mixing enthalpies when the lattice is kept fixed, when only the alloy compositions are relaxed, and when all composition including pure $\mathrm{CrN}$ are allowed to relax. The comparison with the state-of-the-art DLM-MD method shows that the best agreement is obtained when the magnetic induced geometry relaxations are allowed for all concentrations, apparently due to an error cancelation of the spurious magnetic relaxation effect.

In conclusion, it is found that when the electronic and magnetic structures of $\mathrm{Cr}_{1-x} \mathrm{Al}_{x} \mathrm{~N}$ are carefully considered, the cubic solid solution is stabilized with respect to isostructural decomposition at all relevant temperatures in line with experimental observations. The difference to previous work that predicted a tendency for decomposition lies mainly in the treatment of electronic correlations effects. Thus, the $\mathrm{LDA}+\mathrm{U}$ approximation is shown to treat the strong electron correlations of $\mathrm{Cr} 3 d$-orbitals more accurately than the GGA functional when modeling the mixing thermodynamics of cubic $\mathrm{Cr}_{1-x} \mathrm{Al}_{x} \mathrm{~N}$. Furthermore, the DLM-MD method is shown to be a suitable tool to simulate thermodynamic properties of systems with simultaneously present compositional, magnetic, and vibrational disorders.

Financial support from the Swedish Research Council (VR) Grant Nos. 621-2011-4417, 621-2010-3927, and 6212011-4426, the European Research Council Advanced Grant No. 227754, and the Swedish Foundation for Strategic Research (SSF) strategic Research Center MS ${ }^{2}$ E A3 05:192 and Program No. SRL10-0026 is acknowledged. The simulations were carried out at resources provided by the Swedish National Infrastructure for Computing (SNIC).

${ }^{1}$ P. H. Mayrhofer, C. Mitterer, L. Hultman, and H. Clemens, Prog. Mater. Sci. 51, 1032 (2006).

${ }^{2}$ A. E. Reiter, V. H. Derflinger, B. Hanselmann, T. Bachmann, and B. Sartory, Surf. Coat. Technol. 200, 2114 (2005).

${ }^{3}$ P. H. Mayrhofer, A. Hörling, L. Karlsson, J. Sjölén, T. Larsson, C. Mitterer, and L. Hultman, Appl. Phys. Lett. 83, 2049 (2003).

${ }^{4}$ A. Hörling, L. Hultman, M. O. J. Sjölen, and L. Karlsson, Surf. Coat. Technol. 191, 384 (2005).

${ }^{5}$ H. Willmann, P. H. Mayrhofer, P. O. A. Persson, A. E. Reiter, L. Hultman, and C. Mitterer, Scr. Mater. 54, 1847 (2006).

${ }^{6}$ F. Rovere, D. Music, S. Ershov, M. T. Baben, H. G. Fuss, P. H. Mayrhofer, and J. M. Schneider, J. Phys. D: Appl. Phys. 43, 035302 (2010).

${ }^{7}$ H. C. Barshilia, N. Selvakumar, B. Deepthi, and K. S. Rajam, Surf. Coat. Technol. 201, 2193 (2006).

${ }^{8}$ H. Lind, R. Forsén, B. Alling, N. Ghaforr, F. Tasnádi, M. P. Johansson, I. A. Abrikosov, and M. Odén, Appl. Phys. Lett. 99, 091903 (2011).

${ }^{9}$ B. Alling, T. Marten, I. A. Abrikosov, and A. Karimi, J. Appl. Phys. 102, 044314 (2007).

${ }^{10}$ P. H. Mayrhofer, D. Music, T. Reeswinkel, H.-G. Fuss, and J. M. Schneider, Acta Mater. 56, 2469 (2008).

${ }^{11}$ B. Alling, A. V. Ruban, A. Karimi, O. E. Peil, S. I. Simak, L. Hultman, and I. A. Abrikosov, Phys. Rev. B 75, 045123 (2007).

${ }^{12}$ A. Herwadkar and W. R. L. Lambrecht, Phys. Rev. B 79, 035125 (2009).

${ }^{13}$ A. S. Botana, F. Tran, V. Pardo, D. Baldomir, and P. Blaha, Phys. Rev. B 85, 235118 (2012).

${ }^{14}$ B. Alling, T. Marten, and I. A. Abrikosov, Phys. Rev. B 82, 184430 (2010).

${ }^{15}$ D. Gall, C. S. Shin, R. T. H. I. Petrov, and J. E. Greene, J. Appl. Phys. 91, 5882 (2002).

${ }^{16}$ P. A. Bhobe, A. Chainani, M. Taguchi, T. Takeuchi, R. Eguchi, M. Matsunami, K. Ishizaka, Y. Takata, M. Oura, Y. Senba, H. Ohashi, Y. Nishino, M. Yabashi, K. Tamasaku, T. Ishikawa, K. Takenaka, H. Takagi, and S. Shin, Phys. Rev. Lett. 104, 236404 (2010).

${ }^{17}$ X. Y. Zhang, J. S. Chawla, B. M. Howe, and D. Gall, Phys. Rev. B 83, 165205 (2011).

${ }^{18}$ F. Rivadulla, M. Banobre-Lopez, C. X. Quintela, A. Pineiro, V. Pardo, D. Baldomir, M. A. Lopez-Quintela, J. Rivas, C. A. Ramos, H. Salva, J.-S. Zhou, and J. B. Goodenough, Nature Mater. 8, 947 (2009).

${ }^{19}$ B. Alling, T. Marten, and I. A. Abrikosov, Nature Mater. 9, 283 (2010).

${ }^{20}$ S. Wang, X. Yu, J. Zhang, M. Chen, J. Zhu, L. Wang, D. He, Z. Lin, R. Zhang, K. Leinenweber, and Y. Zhao, Phys. Rev. B 86, 064111 (2012).

${ }^{21}$ P. Steneteg, B. Alling, and I. A. Abrikosov, Phys. Rev. B 85, 144404 (2012).

${ }^{22}$ D. M. Ceperley and B. J. Alder, Phys. Rev. Lett. 45, 566 (1980).

${ }^{23}$ V. I. Anisimov, J. Zaanen, and O. K. Andersen, Phys. Rev. B 44, 943 (1991).

${ }^{24}$ S. L. Dudarev, G. A. Botton, S. Y. Savrasov, C. J. Humphreys, and A. P. Sutton, Phys. Rev. B 57, 1505 (1998). 
${ }^{25}$ P. E. Blöchl, Phys. Rev. B 50, 17953 (1994).

${ }^{26}$ G. Kresse and D. Joubert, Phys. Rev. B 59, 1758 (1999).

${ }^{27}$ A. Zunger, S. H. Wei, L. G. Ferreira, and J. E. Bernard, Phys. Rev. Lett. 65, 353 (1990).

${ }^{28}$ J. P. Perdew, K. Burke, and M. Ernzerhof, Phys. Rev. Lett. 77, 3865 (1996).
${ }^{29}$ B. Alling, C. Höglund, R. Hall-Wilton, and L. Hultman, Appl. Phys. Lett. 98, 241911 (2011).

${ }^{30}$ F. Tian, J. D'Arcy-Gall, T. Y. Lee, M. Sardela, D. Gall, I. Petrov, and J. E. Greene, J. Vac. Sci. Technol. A 21, 140 (2003).

${ }^{31}$ F. Rovere, D. Music, J. M. Schneider, and P. H. Mayrhofer, Acta Mater. 58, 2708 (2010). 